\section{A Sequence-amplified Characterized Region Marker for a Single, Dominant Gene in Melon PI 134198 that Confers Resistance to a Unique Race of Podosphaera xanthii in China}

\author{
Longzhou Liu, Youyuan Chen, Zhenghong Su, Hui Zhang, and \\ Weiming $\mathrm{Zhu}^{1}$ \\ Horticultural Research Institute, Shanghai Academy of Agricultural \\ Sciences (SAAS), Shanghai Key Lab of Protected Horticultural. Shanghai, \\ 201106, China \\ Additional index words. Cucumis melo, marker assisted selection, SRAP marker, bulk \\ segregant analysis
}

\begin{abstract}
Melon production in China is threatened by cucurbit powdery mildew incited by Podosphaera xanthii, which can cause severe yield losses. Disease reactions of 10 melon $P$. xanthii race differentials indicated the presence of a unique race of $P$. xanthii, denoted pxCh1, in the Shanghai area. Resistance to $P$. xanthii race pxCh1 in melon PI 134198, which originated from India, was controlled by a single, dominant gene, designated $P \boldsymbol{m}-8$, in a cross with susceptible melon inbred $\mathbf{S 7 1 7}$. A search for a molecular marker linked to $P \boldsymbol{P m}-8$ was initiated using the same cross. Bulk segregant analysis of their $\mathrm{F}_{2}$ progeny revealed one sequence-related amplified polymorphism (SRAP) marker of $148 \mathrm{bp}$ linked to $P m-8$, at $3.9 \mathrm{cM}$. The SRAP segment was recovered, cloned, and sequenced and converted into a sequence-amplified characterized region marker for marker-assisted selection of $\boldsymbol{P m - 8}$ in breeding programs to develop melon cultivars resistant to $\boldsymbol{P}$. xanthii race pxCh1.
\end{abstract}

Cucurbit powdery mildew (CPM) is a common and serious disease of melon worldwide. CPM infection acts as a sink for photosynthates from the leaves, which leads to premature loss of foliage and, subsequently, to loss of fruit quality and yield (Sitterly, 1978). CPM is caused by two fungal species, Podosphaera xanthii (formerly known as Sphaerotheca fuliginea Schlech ex Fr.Poll.) and Golovinomyces cichoracearum (formerly known as Erysiphe cichoracearum DC ex Merat.). $P$. xanthii has been identified as the primary cause of CPM in China (Feng, 1996). Fungicides and resistant varieties are the major means of CPM control. Fungicides are, however, costly and can be rendered ineffective through emergence of insensitive races of the pathogen (McGrath, 2001). Resistant cultivars provide a more economical and environmentally safe control strategy but may select for resistance-breaking races (McCreight, 2006). Few melon cultivars in China are highly resistant to CPM, and development of CPM-

Received for publication 16 Feb. 2010. Accepted for publication 12 July 2010.

This work was supported with a project (08JC1418000, 09UA006, 09ZR142790, 09GZ10320) from the Ministry of Shanghai, China, and NSFC (31000915) of China.

We are grateful to James D. McCreight and Gilda M. Rauscher (USDA-ARS, Salinas, CA) for critical review of the manuscript.

${ }^{1}$ To whom reprint requests should be addressed; e-mail shoujitcl@yahoo.com.cn. makes them less useful for large-scale MAS. Simple and practical markers amenable to high throughput are preferred. Two such markers are sequence-amplified characterized region (SCAR) and cleavage amplification polymorphisms, both of which are highly repeatable and reliable because they are amplified by PCR under highly stringent conditions (Piao et al., 2004; Varshney et al., 2004).

We report inheritance of CPM resistance in Indian melon PI 134198 to a unique race of $P$. xanthii and a new SRAP marker linked to the dominant CPM resistance gene in this accession. The SRAP marker was converted into a SCAR marker, which will help breeders to develop new CPM-resistant melon by MAS

\section{Materials and Methods}

Plant materials. PI 134198 originated from India. It is andromonoecious, resistant to CPM, and has thin, long ellipsoidal fruit that has reddish-colored flesh. S717 is an elite inbred typical of dessert melons grown in Eastern China: andromonoecious, susceptible to CPM, and round fruit with colored flesh. PI 134198 and S717, and their offspring, including $\mathrm{F}_{1}$ (50 plants), $\mathrm{F}_{2}$ (108 plants), and reciprocal backcross progenies formed by backcrossing with the resistant parent $\left(\mathrm{BC}_{\mathrm{PI}} 134198 ; 61\right.$ plants) or by backcrossing with the susceptible parent $\left(\mathrm{BC}_{\mathrm{S} 717}\right.$; 77 plants), were used in this study.

Cucurbit powdery mildew source, inoculation, and evaluation. CPM was collected at the QI Bao Campus, Shanghai Jiaotong University, China, and determined to be $P$. xanthii based on the presence of fibrosin bodies by microscopic observation. The CPM inoculum used in this test was obtained from a monosporic culture and maintained on young plants of melon cv. Milong on isolated greenhouse benches. The CPM isolate was characterized before the genetic study based on the reactions of 10 commonly used race differentials (Table 1; McCreight, 2006). The differential genotypes were arranged in a randomized complete block design with three reps, 15 plants of each differential per rep.

$\mathrm{CPM}$ race characterization and genetic studies were done under the same experimental conditions in a growth chamber set at a 12-h photoperiod (photosynthetic photon flux $\left.=250 \mu \mathrm{mol} \cdot \mathrm{m}^{-2} \cdot \mathrm{s}^{-1}\right)$. Seeds were sown in plastic pots $(8 \times 8 \times 10 \mathrm{~cm}$ deep; one seed per pot). The soil media was an equal (volume basis) mixture of peat, cinders, and perlite. Several heavily infected leaves were soaked in a solution of Tween 20 at $0.02 \%$ ( 4 drops/ L) in deionized water to obtain spores for inoculation. The suspension was filtered through two layers of cheesecloth, and the spore concentration was adjusted to $5 \times 10^{4}$ spores/mL (Block and Reitsma, 2005). Seedlings were inoculated by spraying to runoff when the second true leaves were fully expanded. Humidity was maintained at $75 \pm 10 \%$ relative humidity using a humidifier for $24 \mathrm{~h}$.

Disease index (DI) of the first true leaf of every plant was evaluated 12 days postinoculation in the genetic study. Percentage 
of the leaf area covered with CPM was estimated visually using a 0 (no obvious infection) to 10 (100\% of the leaf covered with CPM) scale (Liu et al., 2008). DI of CPM race differentials were done on an individual plant basis and then averaged within reps. Disease phenotype was considered resistant when DI was 1.0 or less and susceptible when DI was greater than 1.0.

DNA extraction and bulk segregant analysis. Melon genomic DNA was extracted from young leaves using a CTAB method (Doyle and Doyle, 1990). Bulk segregant analysis (BSA) was used to identify SRAP markers linked to the powdery mildew resistance gene (Michelmore et al., 1991). For BSA, six DNA bulks were generated from the $\mathrm{F}_{2}$ population and composed of five plants each; three bulks were comprised of resistant plants on which there was no sporulation on the first three true leaves; the other three bulks included susceptible plants that had an average of covered with mildew greater than $70 \%$ on the first three true leaves.

Sequence-related amplified polymorphism analysis. The PCR reaction was set up in a final volume of $20 \mu \mathrm{L}$ containing $60 \mathrm{ng}$ of DNA, $5.0 \mathrm{pmol}$ of primer, $200 \mu \mathrm{M}$ dNTPs, $1.5 \mathrm{~mm} \mathrm{MgCl}_{2}$, and $0.5 \mathrm{U}$ of Taq polymerase (Promega, Madison, WI) in 1X Taq buffer. The PCR program included an initial denaturing at $94{ }^{\circ} \mathrm{C}$ for $3 \mathrm{~min}$ followed by eight cycles of $94{ }^{\circ} \mathrm{C}$ for $30 \mathrm{~s}, 37^{\circ} \mathrm{C}$ for $30 \mathrm{~s}$, and at $72{ }^{\circ} \mathrm{C}$ for $90 \mathrm{~s}$ and then 35 cycles of $94{ }^{\circ} \mathrm{C}$ for $30 \mathrm{~s}, 48^{\circ} \mathrm{C}$ for $30 \mathrm{~s}$, and $72{ }^{\circ} \mathrm{C}$ for $90 \mathrm{~s}$ with a final extension of $72^{\circ} \mathrm{C}$ for $7 \mathrm{~min}$ (Yuan et al., 2008). The products were separated on $4 \%$ denaturing polyacrylamide gels

Table 1. Disease ratings of melon cucurbit powdery mildew race differentials in a controlled inoculation test.

\begin{tabular}{lcl}
\hline & \multicolumn{2}{c}{ Disease } \\
\cline { 2 - 3 } Differential & Mean rating & Phenotype \\
\hline Iran H & $0.8 \mathrm{~b}$ & Resistant \\
PMR 5 & $1.2 \mathrm{c}$ & Susceptible \\
PMR 45 & $0.0 \mathrm{a}$ & Resistant \\
PMR 6 & $0.0 \mathrm{a}$ & Resistant \\
WMR 29 & $0.7 \mathrm{~b}$ & Resistant \\
MR-1 & $0.0 \mathrm{a}$ & Resistant \\
PI 124112 & $1.4 \mathrm{c}$ & Susceptible \\
Védrantais & $3.2 \mathrm{~d}$ & Susceptible \\
Fuyu 3 & $4.2 \mathrm{e}$ & Susceptible \\
Harukei 3 & $3.9 \mathrm{de}$ & Susceptible \\
\hline
\end{tabular}

zRated on a $0(0 \%$ of the first true leaf area covered with mildew) to $10(100 \%$ of the first true leaf area covered with mildew) scale. Mean of 45 plants for each differential. Means separation using Student's $t$ test; those followed by different letters are significantly different, $P_{0.05}$.

Table 2. Disease reactions of PI 134198, S717, and their $\mathrm{F}_{1}$ and segregating generations to Podosphaera xanthii race pxCh1.

\begin{tabular}{lccccc}
\hline Line or population & Resistant & Susceptible & Expected ratio & $\chi^{2}$ & $P$ \\
\hline PI 134198 & 30 & & All resistant & & \\
S717 & 46 & 30 & All resistant & & \\
F $_{1}$ & 74 & 4 & All resistant & & \\
F $_{2}$ & 58 & 34 & $3: 1$ & 2.41 & 0.18 \\
BC $_{\text {PI } 134198}$ & 36 & 41 & All resistant & & $0: 22$ \\
BC $_{\text {S717 }}$ & & & $1: 1$ & 0.68 \\
\hline
\end{tabular}

and visualized using silver staining (Xu et al., 2002). The primer combinations that generated polymorphic bands between the bulks were tested on the bulked individuals to eliminate false-positive markers.

Sequence-amplified characterized region primer design and polymerase chain reaction analysis of sequences. Bands containing the targeted SRAP fragment were exercised from sodium dodecyl sulphate-polyacrylamide gels and placed in $0.5-\mathrm{mL}$ Eppendorf tubes. After adding $30 \mu \mathrm{L}$ of $\mathrm{ddH}_{2} \mathrm{O}$, the gel slices were crushed with a pipette tip and held at $95^{\circ} \mathrm{C}$ for $10 \mathrm{~min}$. The tubes were centrifuged at a speed of $10,000 \mathrm{rpm}$ for $1 \mathrm{~min}$ and $1 \mu \mathrm{L}$ of the supernatant was used as template for selective amplification with the same primer combination. The reamplified PCR product was analyzed in a $1.5 \%$ agarose gel. A UNIQ10 EZ Spin Column DNAGel Extraction Kit (Sangon, Shanghai, China) and a pGEM-T Easy Vector (Promega) was used to purify and clone the fragments into the Escherichia coli DH5 $\alpha$. Recombinant plasmid DNA was isolated and sequenced by Sangon Corp. (Shanghai, China). A pair of oligonucleotide primers was designed based on the sequence of the cloned fragment using Premier 5.0 software (Premier Biosoft Intl., Palo Alto, CA) and synthesized by Sangon Corp. PCR amplification with the SCAR primers was performed in a $10-\mu \mathrm{L}$ reaction containing 20 ng template DNA, 5.0 pmol each SCAR primer, $100 \mu \mathrm{M} d \mathrm{dTPs}, 2.5 \mathrm{mM} \mathrm{MgCl}_{2}$, and $0.2 \mathrm{U}$ of Taq polymerase (Promega) in $1 \times$ Taq buffer, $7.7 \mu \mathrm{L}$ of $\mathrm{ddH}_{2} \mathrm{O}$, Samples were overlaid with mineral oil and the PCR protocol was: $94{ }^{\circ} \mathrm{C}$ for $4 \mathrm{~min}, 30$ cycles: at $94^{\circ} \mathrm{C}$ for 30 $\mathrm{s}$, at $55^{\circ} \mathrm{C}$ for $30 \mathrm{~s}$, and at $72{ }^{\circ} \mathrm{C}$ for $60 \mathrm{~s}$, final extension $72{ }^{\circ} \mathrm{C}$ for $5 \mathrm{~min}$. Amplified products were separated in $2.5 \%$ agarose gels. Electrophoresis was performed at $100 \mathrm{~V}$ and maximum amperage for $1 \mathrm{~h}$. Gels were stained with ethidium bromide and photographed with a digital, gel documentation system.

Segregation data were subjected to $\chi^{2}$ analysis to ascertain the goodness of fit between the expected and observed segregation ratios for a single dominant gene and for the phenotypic data, analysis between the SCAR markers, and the CPM resistance locus.

The SCAR marker was tested on 74 resistant and 34 susceptible $\mathrm{F}_{2}$ plants. Linkage of PM resistance locus was performed with the software package MAPMAKER/EXP, Version 3.0 (Lander et al., 1987). The recombinant frequencies between the CPMresistant locus and molecular markers were calculated through two-point tests and link- age map was constructed by three-point or multiple-point tests with a minimum limit of detection threshold of 3.0. The recombination values were converted into centiMorgans (cM) using the Kosambi mapping function. For mapping the marker, the $F_{2}$ population was also analyzed with the microsatellite markers (CMBR8, CMBR120, TJ29, CMBR111, and CMBR150) previously described by Fukino et al. (2008) as linked to powdery mildew resistance were also evaluated. PCR amplification was carried out following the same protocol of the SCAR primer, and the genetic linkage map was drawn using MapChart 2.2 software (Voorrips, 2002).

\section{Results}

Cucurbit powdery mildew race evaluation. The isolate of CPM used in this research was unique based on the reaction pattern of the 10 differentials (Table 1) and was denoted as pxCh1. The key difference between this isolate and previously reported isolates was the resistant reaction of Iran $\mathrm{H}$ in contrast to the susceptible reactions of 'Védrantais' and 'Fuyu 3' (Table 1). This reaction pattern was distinct from any patterns of the known races (McCreight, 2006).

Genetic analysis for powdery mildew resistance. The $\mathrm{F}_{1}$ was resistant, suggesting that CPM resistance of PI 134198 was controlled by a single, dominant gene (Table 2). The $F_{2}$ populations segregated 74 resistant to 34 susceptible in a good fit to a 3:1 ratio (Table 2) expected for a single dominant resistance gene (Table 2). The $\mathrm{BC}_{\mathrm{PI}} 134198$ plants were resistant with three exceptions, whereas the $\mathrm{BC}_{\mathrm{S} 717}$ segregated in a good fit to the expected 1:1 ratio (Table 2). This CPM resistance gene will be referred to henceforth as $P m-8$.

Identification of a sequence-related amplified polymorphism marker linked to the Pm- 8 gene. The 700 primer combinations used to screen the parental DNA in SRAP analysis amplified 8146 discrete genomic fragments (average 10 to 12 products per primer pair). Polymorphisms were amplified with 55 primer pairs $(7.8 \%)$ resulting in 246 polymorphic bands $(3.0 \%)$ between the resistant and susceptible parental genotypes. All primer pairs that generated polymorphic bands were tested on the resistant and susceptible bulks. SRAP bands present in one pool and absent in the other were regarded as candidate markers linked to $P m-8$. One primer combination (E-05/M-03) produced a 148-bp DNA fragment that was found only in the resistant parent, resistant bulks, and resistant $\mathrm{F}_{2}$ plants.

Sequence analysis. The SRAP marker E-05/M-03 linked to $P m-8$ was cloned with the objective of converting it into a simple PCR-based marker. The polymorphic amplified DNA band corresponding to the SRAP marker was reamplified and a single band with the expected size was observed on an agarose gel. The band was then purified and sequenced and found to be $148 \mathrm{bp}$ long and did not show significant homology to any other known gene. 
Sequence-amplified characterized region analysis and linkage analysis. Based on the sequence of the cloned fragment, a pair of oligonucleotide primers was designed with Primer 5.0 software as follows: forward primer, 5' -CCCTATGCTCATTAACTTCG$3^{\prime}$; reverse primer, $5^{\prime}$-GCTGCATAATGCCTAGCTA-3'.

These SCAR primers amplified a single, 124-bp band named SCAR0305 in the CPMresistant parent and $\mathrm{F}_{2}$ plants (Fig. 1). This band was absent in S717, the susceptible parent. SCAR0305 was present in 73 of the 74 CPM-resistant plants and absent in all 34 susceptible $\mathrm{F}_{2}$ plants.

Mapping of the Pm-8 linked markers. The analysis of the segregation data from the two markers (SCAR0305 and CMBR150) on the $108 \mathrm{~F}_{2}$ individuals and the resistance trait allowed us to assign the position of these markers in the melon genomic region of Linkage Group VII (Fukino et al., 2008) surrounding the $P m-8$ locus. Four other markers (CMBR8, CMBR120, TJ29, and CMBR111) were not linked with $P m-8$. The genetic linkage distances of $P m-8$ with SCAR0305 and CMBR150 were 3.90 and $28.60 \mathrm{cM}$, respectively.

\section{Discussion}

Powdery mildew has been a serious disease of cucurbit plants since ancient times (Ballantyne, 1975). Melon was first cultivated in China 2500 years ago (Wang et al., 2005), but there are no previous scientific reports of CPM races on melon from China, a contrast to the United States and France (McCreight, 2006; McCreight et al., 1987). A unique race of $P$. xanthii, pxCh1, was identified in China based on the reaction pattern of 10 commonly used melon race differentials (McCreight, 2006). High-level resistance to pxCh1 was observed on Iran $\mathrm{H}$, which is generally susceptible to cucurbit CPM (McCreight, 2006; Pitrat, 1998). Krístková et al. (2004) reported incomplete resistance in Iran $\mathrm{H}$ against two strains of $P$. xanthii and complete resistance to one strain of $G$. cichoracearum. Based on our results and those of Krístková et al. (2004), we concluded that $P$. xanthii isolate pxCh1 is a new race and is the first reported race of $P$. xanthii on melon in China.

Seventeen dominant, CPM resistance genes were included in the latest melon gene list (Pitrat, 2006). This list does not include the six or so recessive and codominant CPM resistance genes reported in melon (McCreight, 2003; McCreight and Coffey, 2007; Pitrat and Besombes, 2008). A QTL for CPM resistance to $P$. xanthii race 1 and N1 was recently reported in melon breeding line AR 5 (Fukino et al., 2008). Fukino et al. (2008) reported microsatellite markers CMBR8, CMBR120, TJ29, CMBR111, and CMBR150 linked to the CPM QTL locus in AR 5 in response to $P$. xanthii races 1 and $\mathrm{N} 1$. Only CMBR 150 was linked with $P m-8$ locus in PI 134198 in linkage group VII of the Fukino et al. (2008) map. These results from distinctly different resistance sources and $\mathrm{CPM}$ races indicate that there is a resistance gene cluster in linkage group VII or the allelic genes for $\mathrm{Pm}-8$ can be found on the linkage group VII of the map (Fukino et al., 2008).

SRAP markers have become widely used in developing genetic maps, for MAS breeding programs (Mukhlesur et al., 2007; Sun et al., 2007; Yuan et al., 2008), and for saturating genomic regions of interest with markers for the ultimate goal of map-based cloning of target genes. Selection efficiency can, however, be improved when a SRAP marker is transformed into a SCAR marker (Mukhlesur et al., 2007).

The result from the present research, in which a 124-bp band was present in 73 of the 74 resistant $\mathrm{F}_{2}$ plants, but absent in all of the 34 susceptible $\mathrm{F}_{2}$ plants, confirms the tight linkage of the SCAR marker (SCAR0305) to $P m-8$ and indicates that this marker may be useful for MAS. This marker is expected to facilitate development of CPM-resistant melon cultivars carrying the relevant gene for the resistant trait and will be useful for map-based cloning of CPM resistance in melon.

The study presented here focused mainly on the development of molecular markers tightly linked to the $P m-8$ locus. We are now examining these markers in a larger population to estimate the genetic distance more accurately and to determine their relative position from the $P m-8$ gene. If one or more markers are found linked with the $P m-8$ locus more closely in the larger population, then they will provide a basis for eventual positional cloning of the Pm-8 gene. The whole genome sequence of melon will soon be available, and we believe it will facilitate discovery of markers more closely linked to the $P m-8$ locus and to the cloning of more genes in melon by position cloning.

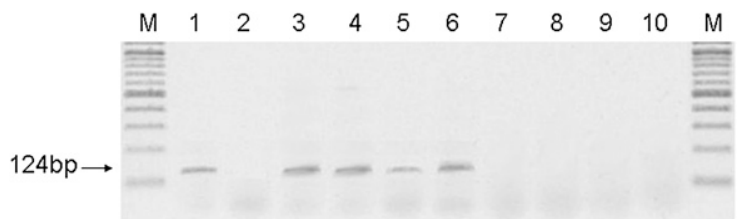

Fig. 1. Electrophoresis patterns of polymerase chain reaction-amplified with genomic DNA of 10 melon samples, which was used as a template DNA to test candidate SCAR primer pairs (SCAR0305): M, molecular marker, 100-bp ladder; lane 1, CPM-resistant parent (PI 134198); lane 2, CPM-susceptible parent (S717); lanes 3 to 6, CPM-resistant $\mathrm{F}_{2}$ plants; lanes 7 to 10 , CPM-susceptible $\mathrm{F}_{2}$ plants. SCAR, sequence-amplified characterized region; CPM, cucurbit powdery mildew.

\section{Literature Cited}

Ballantyne, B. 1975. Powdery mildew on cucurbitaceae, identity, distribution, host range and sources of resistance. Proc. Linn. Soc. N. S. W. 99:100-120.

Block, C.C. and K.R. Reitsma. 2005. Powdery mildew resistance in the US national plant germplasm system cucumber collection. HortScience 40:416-420.

Doyle, J.J. and J.L. Doyle. 1990. Isolation of plant DNA from fresh tissue. Focus 12:13-15.

Fan, Z., M.D. Robbins, and J.E. Staub. 2006. Population development by phenotypic selection with subsequent marker-assisted selection for line extraction in cucumber (Cucumis sativus L.). Theor. Appl. Genet. 112:843-855.

Feng, D.X. 1996. The recent progress in resistance powdery mildew breeding of cucurbitaceous. China Vegetable 7:55-59 [in Chinese with English summary].

Ferriol, M., B. Pico, and F. Nuez. 2003. Genetic diversity of a germplasm collection of of Cucurbita pepo using SRAP and AFLP markers. Theor. Appl. Genet. 107:271-282.

Fukino, N., T. Ohara, A.J. Monforte, M. Sugiyama, Y. Sakata, M. Kunihisa, and S. Matsumoto. 2008. Identification of QTLs for resistance to powdery mildew and SSR markers diagnostic for powdery mildew resistance genes in melon (Cucumis melo L.). Theor. Appl. Genet. 118: 165-175.

Krístková, E., A. Lebeda, and B. Sedláková. 2004. Virulence of Czech cucurbit powdery mildew isolates on Cucumis melo genotypes MR-1 and PI 124112. Sci. Hort. 99:257-265.

Lander, E., P. Green, J. Abrahamson, A. Barlow, M. Daley, S. Lincoln, and L. Newburg. 1987. MAPMAKER: An interactive computer package for constructing primary genetic linkage maps of experimental and natural populations. Genomics 1:174-181.

Li, G. and C.F. Quiros. 2001. Sequence-related amplified polymorphism (SRAP), a new marker system based on a simple PCR reaction: Its application to mapping and gene tagging in Brassica. Theor. Appl. Genet. 103:455-461.

Liu, L.Z., X.J. Yuan, R. Cai, J.S. Pan, H.L. He, L.H. Yuan, Y. Guan, and L.H. Zhu. 2008. Quantitative trait loci for resistance to powdery mildew in cucumber under seedling spray inoculation and leaf disc infection. J. Phytopathol. 156:691-697.

McCreight, J.D. 2003. Genes for resistance to powdery mildew races 1 and 2 US in melon. P1 313970. HortScience 38:591-594.

McCreight, J.D. 2006. Melon-powdery mildew interactions reveal variation in melon cultigens and Podosphaera xanthii races 1 and 2. J. Amer. Soc. Hort. Sci. 131:59-65.

McCreight, J.D. and M.D. Coffey. 2007. Resistance to a new race of the cucurbit powdery mildew present in Arizona and California. HortScience 42:1013.

McCreight, J.D., M. Pitrat, C.E. Thomas, A.N. Kishaba, and G.W. Bohn. 1987. Powdery mildew resistance genes in muskmelon. J. Amer. Soc. Hort. Sci. 112:156-160.

McGrath, M.T. 2001. Fungicide resistance in cucurbit powdery mildew: Experiences and challenges. Plant Dis. 85:236-245.

Michelmore, R.W., R.V. Paran, and I. Kesseli. 1991. Identification of markers linked to disease resistance genes by bulked segregant analysis: A rapid method to detect markers in specific genomic regions by using segregating populations. Proc. Natl. Acad. Sci. USA 88: 9828-9833.

Mukhlesur, R., B.E. McVetty, and G.Y. Li. 2007. Inheritance of seed coat color genes of Brassica 
napus (L.) and tagging the genes using SRAP molecular markers. 12th International Rapeseed Conference, 26-30 Mar., Wuhan, China.

Mutlu, N., F.H. Boyaci, M. Göçmen, and K. Abak. 2008. Development of SRAP, SRAP-RGA, RAPD and SCAR markers linked with a fusarium wilt resistance gene in eggplant. Theor. Appl. Genet. 117:1303-1312.

Piao, Z.Y., Y.Q. Deng, S.R. Choi, Y.J. Park, and Y.P. Lim. 2004. SCAR and CAPS mapping of $\mathrm{CRb}$, a gene conferring resistance to Plasmodiophora brassicae in Chinese cabbage (Brassica rapa ssp. pekinensis). Theor. Appl. Genet. 108:1458-1465.

Pitrat, M. 2006. 2006 gene list for melon. Cucurbit Genet. Coop. Rept. 29:142-163.

Pitrat, M. and D. Besombes. 2008. Inheritance of Podosphaera xanthii resistance in melon line '90625', p. 135-142. In: Pitrat, M. (ed.). Cucurbitaceae. IXth Eucarpia Meeting on Genetics and Breeding of Cucurbitaceae. INRA, Avignon, France.
Pitrat, M., C. Dogimont, and M. Bardin. 1998. Resistance to fungal diseases of foliage in melon, p. 167-173. In: McCreight, J.D. (ed.). Cucurbitaceae '98: Evaluation and enhancement of cucurbit germplasm. ASHS Press, Alexandria, VA.

Sitterly, W.R. 1978. Powdery mildews of cucurbits, p. 359-379. In: Spencer, D.M. (ed.). The powdery mildews. Academic Press, New York, NY.

Sun, Z.D., Z.N. Wang, J.X. Tu, J.F. Zhang, F.Q. Yu, P.B.E. McVetty, and G.Y. Li. 2007. An ultradense genetic recombination map for Brassica napus, consisting of 13551 SRAP markers. Theor. Appl. Genet. 114:1305-1317.

Tanksley, S.D., N.D. Young, A.H. Paterson, and M.W. Bonierbale. 1989. RFLP mapping in plant breeding: New tools for an old science. Bio/Technology. 7:257-264.

Varshney, A., T. Mohapatra, and R.P. Sharma. 2004. Development and validation of CAPS and AFLP markers for white rust resistance gene in Brassica juncea. Theor. Appl. Genet. 109:153-159.

Voorrips, R.E. 2002. MapChart: Software for the graphical presentation of linkage maps and QTLs. J. Hered. 93:77-78.

Wang, J.S., S.H. Song, X.W. Tang, and G.L. Chen. 2005. Genetics and molecular marker of the gene for disease resistance to powdery mildew on Cucumis melo L. Acta Agriculturae BorealiSinica 20:89-92.

Xu, S.B., Y.F. Tao, Z.Q. Yang, and J.Y. Chu. 2002. A simple and rapid method used for silver staining and gel preservation. Hereditas (Beijing) 24:335-336.

Yuan, X.J., J.S. Pan, R. Cai, Y. Guan, L.Z. Liu, W.W. Zhang, Z. Li, H.L. He, C. Zhang, L.T. Si, and L.H. Zhu. 2008. Genetic mapping and QTL analysis of fruit and flower related traits in cucumber (Cucumis sativus L.) using recombinant inbred lines. Euphytica 164:473491. 